\title{
Sistem Pelaporan Identifikasi Karakter Seorang Anak Berdasarkan Pola Sidik Jari dan Sudut Tangan
}

\author{
Muhammad Gufron ${ }^{*}$, Eko Budi Cahyono ${ }^{2}$, Gita Indah Marthasari ${ }^{3}$ \\ 1,2,3 Teknik Informatika/Universitas Muhammadiyah Malang \\ m.gufron17@gmail.com¹, ekobudi@umm.ac.id², gitaindah@umm.ac.id ${ }^{3}$
}

\begin{abstract}
Abstrak
Analisis sidik jari tangan merupakan salah satu metode biometrik untuk mengetahui karakter seseorang. Analisis sidik jari dikembangkan sebagai salah satu metode untuk mengetahui fungsi kerja otak yang paling dominan yang mempengaruhi potensi genetik seseorang. Melalui interpretasi pola sidik jari dan pengukuran garis-garis diujung setiap jari tangan dapat terbaca potensi, motivasi, gaya belajar, gaya bekerja, bahkan potensi stress seseorang yang terbawa sejak lahir. Adanya hubungan antara pola sidik jari dengan karakter seseorang menimbulkan ide untuk membuat suatu sistem yang dapat digunakan untuk analisa karakteristik seorang anak berdasarkan tipe pola sidik jari yang dimilikinya.

Sistem dapat Melakukan analisis berdasarkan pola sidik jari dan sudut tangan untuk mendapatkan tipe kecedasan, gaya belajar dan karakter pada anak dengan tujuan agar dapat mempermudah user dalam menganalisa secara otomatis berdasarkan pola sidik jari dan sudut tangan yang di inputkan hingga mendapatkan output tipe kecedasan, gaya belajar dan karakter pada anak.
\end{abstract}

Kata Kunci: Sistem Analisa Sidik Jari, Sistem Analisa Kecerdasan

\begin{abstract}
Hand-fingerprint analysis is one of the biometric methods for knowing a person's character. Fingerprint analysis was developed as one of the methods to find out the most dominant brain functions affecting one's genetic potential. Through the interpretation of fingerprint patterns and measurements of the lines at the end of each finger can be read potential, motivation, learning style, work style, even the potential stress of a person who was born from birth. The existence of the relationship between the pattern of fingerprint with the character of a person raises the idea to create a system that can be used to analyze the characteristics of a child based on the type of fingerprint pattern it has.

The system can perform analysis based on the fingerprint and hand angle patterns to get the type of spelling, learning style and character in the child in order to facilitate user in analyzing automatically based on fingerprint pattern and hand corner of input to get the output type of spiritedness, learning style and character in child.
\end{abstract}

Keywords: Fingerprint Analysis System, Intelligence Analysis System

\section{Pendahuluan}

Usaha manusia untuk mengenali dan memahami karakter dirinya sendiri dan orang-orang di sekitarnya sudah berlangsung sejak lama. Berbagai cara dan metode dikembangkan untuk maksud tersebut, sehingga bermunculan sejumlah alat atau metode untuk memahami lebih mendalam tentang perilaku manusia. Penggunaan biometric untuk pengenalan diri membawa warna lain dalam bagaimana manusia menemukan jati-dirinya. Salah satu teknologi biometrik adalah sidik jari tangan.

Analisis sidik jari tangan merupakan salah satu metode biometrik untuk mengetahui karakter seseorang. Analisis sidik jari dikembangkan sebagai salah satu metode untuk mengetahui fungsi kerja otak yang paling dominan yang mempengaruhi potensi genetik seseorang. Melalui interpretasi pola sidik jari dan pengukuran garis-garis diujung setiap jari tangan dapat terbaca potensi, motivasi, gaya belajar, gaya bekerja, bahkan potensi stress seseorang yang terbawa sejak lahir [1].

Pada tahun 1943, Cummins dan Midlo dalam bukunya menemukan bahwa karakter dan temperamen berkorelasi dengan analisis dermatoglyphics (Dermatoglyphics adalah studi ilmiah 
tentang sidik jari atau "pola kulit" dan kaitannya dengan tipe kepribadian). Hasil temuan mereka merupakan cikal bakal dari metode analisis sidik jari yang dihubungkan dengan potensi, karakter, motivasi, dan gaya belajar setiap individu [2].

Studi ilmiah yang mendalam pertama kali tentang klasifikasi pola sidik jari dibuat oleh Francis Galton, yang membagi pola sidik jari menjadi tiga kelas utama (arch, loop, dan whorl) dan selanjutnya setiap kategori dibagi ke dalam subkategori [3].

Pada penelitian sebelumnya pengenalan kepribadian berdasarkan pola sidik jari yang dilakukan oleh I Gede Sujana, Dkk pada Tahun 2014. Menjelaskan tentang pengembangan sistem klasifikasi kepribadian berdasarkan pola sidik jari fuzzy LVQ memiliki tingkat akurasi tertinggi $98.78 \%$ dan fuzzy backpropagation tertinggi sebesar $93.30 \%$. pada penelitian tersebut hanya mengenali kepribadian. Perbedaan pada penelitian ini adalah proses pengenalan tidak hanya pada kepribadian namun lebih ke Pendidikan seperti pengenalan dominasi otak, tipe kecerdasan, gaya belajar dan karakter kepribadian sedangkan metode pengenalan di ambil dari pakar tempat penelitian [4].

Adanya hubungan antara pola sidik jari dengan karakter seseorang menimbulkan ide untuk membuat suatu sistem yang dapat digunakan untuk analisa karakteristik seorang anak berdasarkan tipe pola sidik jari yang dimilikinya.

\section{Tinjauan Pustaka}

\subsection{Pengenalan Pola (Pattern Recognition)}

Menurut Polikar (2006:1), pengenalan pola atau pattern recognition berasal dari kebutuhan mesin untuk mengenali objek secara otomatis, sinyal atau gambar, atau kebutuhan untuk pengambilan keputusan secara otomatis berbasis sekumpulan parameter [5].

Tujuan dari sistem pengenalan pola adalah memperkirakan label yang berhubungan dengan vektor fitur yang diberikan berdasarkan beberapa pengetahuan yang didapat sebelumnya melalui pelatihan atau training.

\subsection{Sidi Jari}

Menurut Komarinski (2005:3), Fingerprint atau sidik jari adalah sebuah biometric yang telah digunakan secara sistematik untuk identifikasi selama 100 tahun yang telah diukur, diduplikasi dan diperiksa secara ekstensif, sebuah biometric yang tidak berubah dan relatif mudah untuk diambil. Pada jari atau ibu jari, ridge-ridge membentuk tiga buah pola, yakni loops, whorls dan arches [6].

\subsection{Kecerdasan}

Gardner Howard mengemukan bahwa intelegensia atau kecerdasanbukanlah suatu kesatuan tunggal yang bisa diukur secara sederhana yang bisa diukur dengan tes IQ. Intelegensia dapat ditingkatkan dan berkembang sepanjang sejarah hidup manusia. Gardner mendefinisikan kecerdasan sebagai suatu kapasitas untuk memecahkan permasalahanm atau membentuk produk yang bernilai dalam satu atau lebih latar budaya [7].

Kecerdasan luar biasa yang dimiliki manusia ada sepuluh, diantaranya adalah: Kecerdasan Linguistik, Logika Matematis, Musikal, Kinestetik Tubuh, Visual Spasial, Interpersonal, Intrapersonal, Naturalis, Spiritual/Eksistensial, Moral [8].

\subsection{PHP : Hypertext Preprocessor (PHP)}

PHP merupakan sebuah bahasa scripting yang terpasang pada HTML. Tujuan utama penggunaan bahasa ini adalah untuk memungkinkan perancang web menulis halaman web dinamik dengan cepat [9].

Kode PHP disimpan sebagai plain text dalam format ASCII, sehingga kode PHP dapat ditulis hampir di semua editor text seperti windows notepad, windows wordpad, Adobe Dreamweaver CS5 dll. Kode PHP adalah kode yang disertakan di sebuah halaman HTML dan kode tersebut dijalankan oleh server sebelum dikirim ke browser.

\section{Metode Penelitian}

\subsection{Kebutuhan Data}

Data yang akan digunakan dalam penelitian ini seperti pada Tabel 1 berikut. 


\begin{tabular}{cc} 
& Tabel 1. Data Jari \\
\hline No & Jari \\
\hline 1 & Jari Kelingking kiri \\
2 & Jari manis kiri \\
3 & Jari tengah kiri \\
4 & Jari telunjuk kiri \\
5 & Ibu jari kiri \\
6 & lbu jari kanan \\
7 & Jari telunjuk kanan \\
8 & Jari tengah kanan \\
9 & Jari manis kanan \\
10 & Jari klinking kanan \\
\hline
\end{tabular}

Pada Tabel 1 diatas merupakan data yang akan diolah, data yang di ambil dari setiap jari adalah data sidik jari yang kemudian akan di golongkan dalam bentuk pattern.

\begin{tabular}{cc}
\multicolumn{2}{c}{ Tabel 2. Data Sudut Tangan } \\
\hline No & Sudut Tangan \\
\hline 1 & Sudut Tangan Kiri \\
2 & Sudut Tangan Kanan \\
\hline
\end{tabular}

Data sudut tangan pada Tabel 2 diatas merupakan data yang akan digunakan untuk mengetahui dominasi otak, sudut tangan akan di hitung berdasarkan rumus tertentu untuk mendapatakan nilai presentasi dominasi otak kiri atau dominasi otak kanan.

\begin{tabular}{cc} 
& Tabel 3. Data Pattern Jari \\
\hline No & Keterangan Pattern Jari \\
\hline 1 & Logis Matematis \\
2 & Logis Spasial \\
3 & Linguistik \\
4 & Musical \\
5 & Body Kinestetik \\
6 & Interpersonal \\
7 & Naturalis \\
8 & Intra Personal \\
\hline
\end{tabular}

Data pattern jari pada Tabel 3 merupakan pengelompokan data sidik jari berdasarkan pattern, data pattern jari dikelompokkan berdasarkan nilai yang di dapat dari sidik jari.

\begin{tabular}{cc} 
& Tabel 4. Hasil yang Analisa \\
\hline No & Hasil Output \\
\hline 1 & Dominasi Otak \\
2 & Tipe Kecerdasan \\
3 & Gaya Belajar \\
4 & Karakter Kepribadian \\
\hline
\end{tabular}

Dari data inputan pada Tabel 1, Tabel 2, dan Tabel 3 maka akan di proses melalui sistem dan persamaan yang telah di tentukan oleh pakar sehingga menghasilkan output yang terdiri dari dominasi otak, type kecerdasan, gaya belajar, karakter dan kepribadian seperti pada Tabel 4 diatas.

\subsection{Use-case Diagram}

Berdasarkan usecase diagram pada Gambar 1 diatas maka dapat di jelaskan fungsi masing-masing atribut, penjelasan dapat di lihat pada Tabel 5 berikut. 


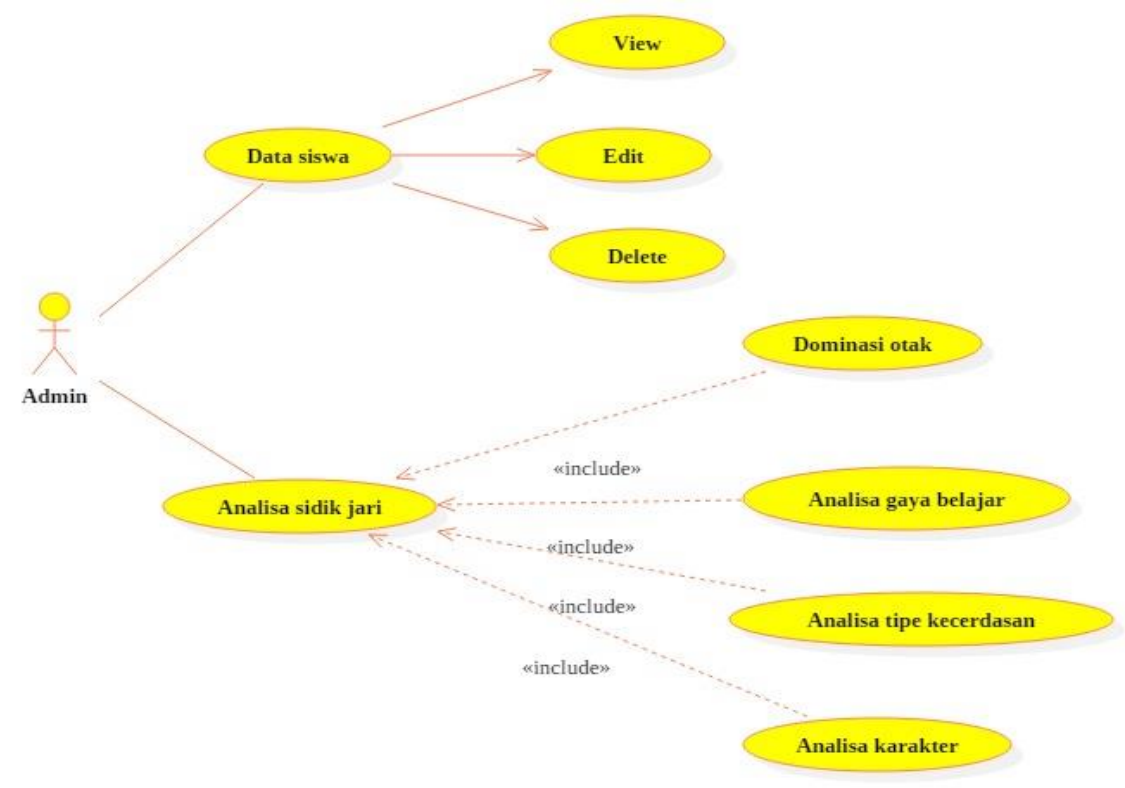

Gambar 1. Usecase Diagram

Tabel 5. Keterangan Usecase

\begin{tabular}{|c|c|}
\hline Atribut & Keterangan \\
\hline Admin & $\begin{array}{l}\text { Admin merupakan actor yang akan } \\
\text { menjalankan aplikasi }\end{array}$ \\
\hline Data siswa & $\begin{array}{l}\text { Data siswa merupakan menu aplikasi } \\
\text { yang berfungsi menampilkan, meng edit } \\
\text { dan menghapus data siswa yang } \\
\text { pernah melakukan Analisa sidik jari } \\
\text { Analisa sidik jari berfungsi untuk } \\
\text { menganalisa sidik jari yang terdiri dari }\end{array}$ \\
\hline Analisa sidik jari & $\begin{array}{l}\text { Dominasi otak, Analisa gaya belajar, } \\
\text { Analisa tipe kecerdasan, dan Analisa } \\
\text { karakter }\end{array}$ \\
\hline
\end{tabular}

\subsection{Arsitektur Sistem}

Analisis sidik jari di mulai dari admin melakukan proses input data patern jari dan sudut tanganm kemudian sistem akan melakukan proses analisis terhadap inputan yang di inpukan oleh admin, hasil dari sistem akan di tampilkan kepada user dalam bentuk laporan hasil Analisa yang terdiri dari hasil Analisa tipe kecerdasan, hasil Analisa gaya belajar, dan hasil Analisa karakter.

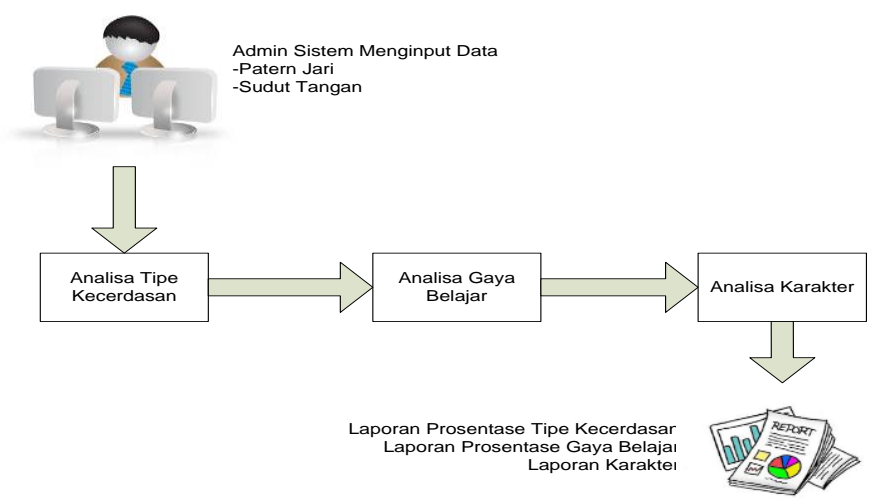

Gambar 2. Arsitektur Sistem

REPOSITOR, Vol. 1, No. 1, November 2019: 17-26 


\subsection{Flowchart}

Dari Gambar 2 diatas jika di gambarkan dalam bentuk alur data dapat di lihat seperti pada gambar flowchart seperti pada Gambar 3 berikut.

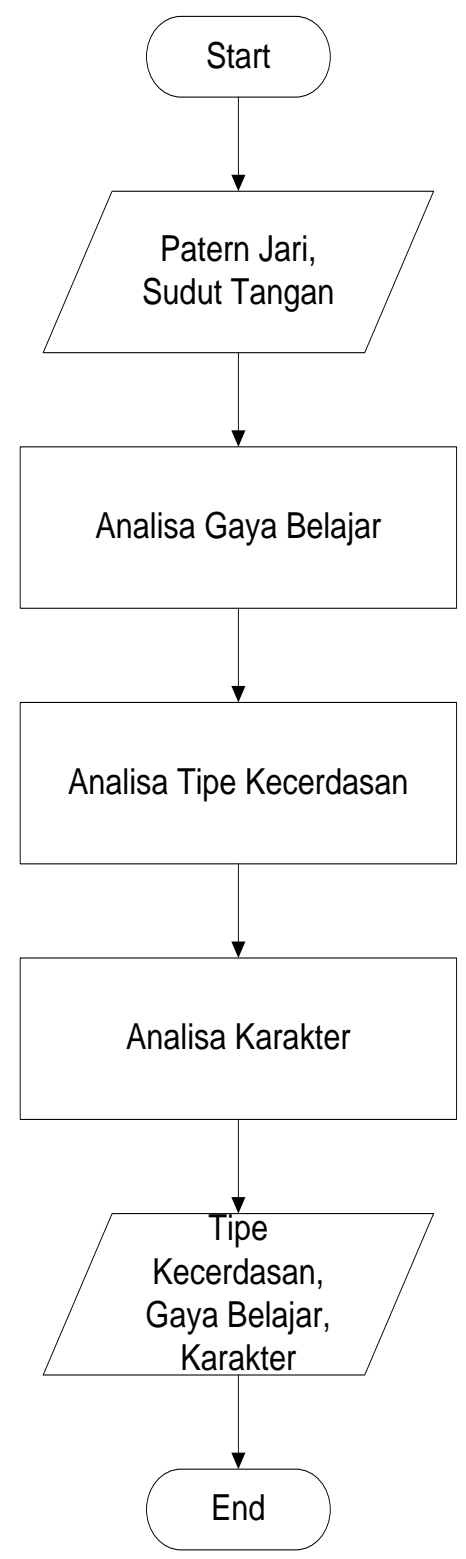

Gambar 3. Flowchart Gambaran Sistem

\subsection{Diagram Konteks}

Diagram konteks berisi gambaran umum (secara garis besar) sistem yang akan dibuat. Secara kalimat, dapat dikatakan bahwa diagram konteks ini berisi "siapa saja yang memberi data (dan data apa saja) ke sistem, serta kepada siapa saja informasi (dan informasi apa saja) yang harus dihasilkan sistem. "Jadi, yang dibutuhkan adalah :

1. Siapa saja pihak yang akan memberikan data ke sistem,

2. Data apa saja yang diberikannya ke sistem,

3. kepada siapa sistem harus memberi informasi atau laporan, dan

4. apa saja isi/ jenis laporan yang harus dihasilkan sistem.

Kata "Siapa" di atas dilambangkan dengan kotak persegi (disebut dengan terminator), dan kata "apa" di atas dilambangkan dengan aliran data (disebut dengan data flow), dan kata "sistem" dilambangkan dengan lingkaran (disebut dengan process) [10]. Gambar 4 merupakan keseluruhan alur sistem. 


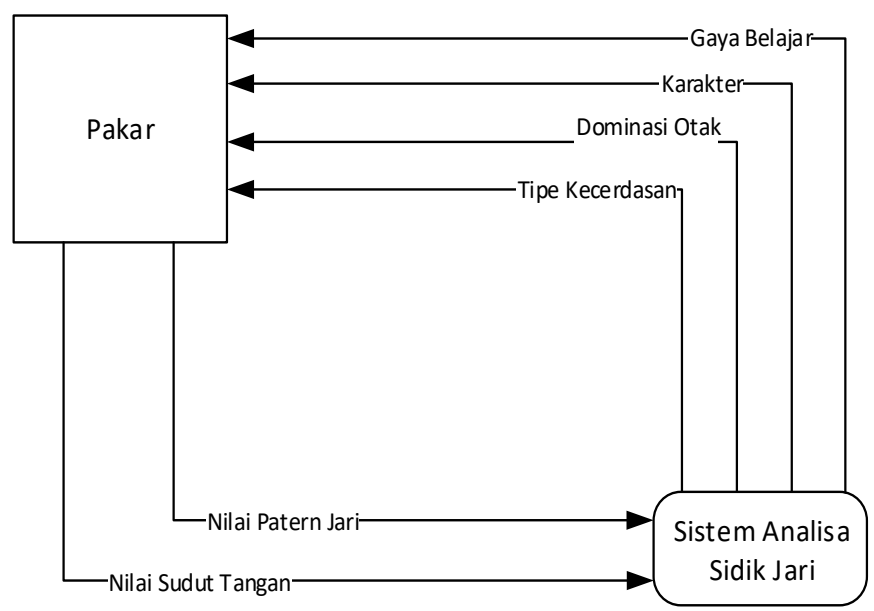

Gambar 4. Diagram Konteks

\subsection{Data Flow Diagram Level 1}

Tujuan dari diagram Level 1 adalah untuk "memperinci" sebuah sistem menjadi "prosesproses" yang harus dilakukan 'orang dalam.' Atau jika dibuat dalam kalimat adalah : "Apa saja proses yang harus dilakukan agar mencapai sistem tersebut ?." Jadi, diagram ini adalah kelanjutan dari diagram konteks, yang "memperbanyak lingkaran," sedangkan untuk (jumlah dan isi) terminator serta (jumlah dan isi) data flow dari dan ke terminator tersebut harus tetap.

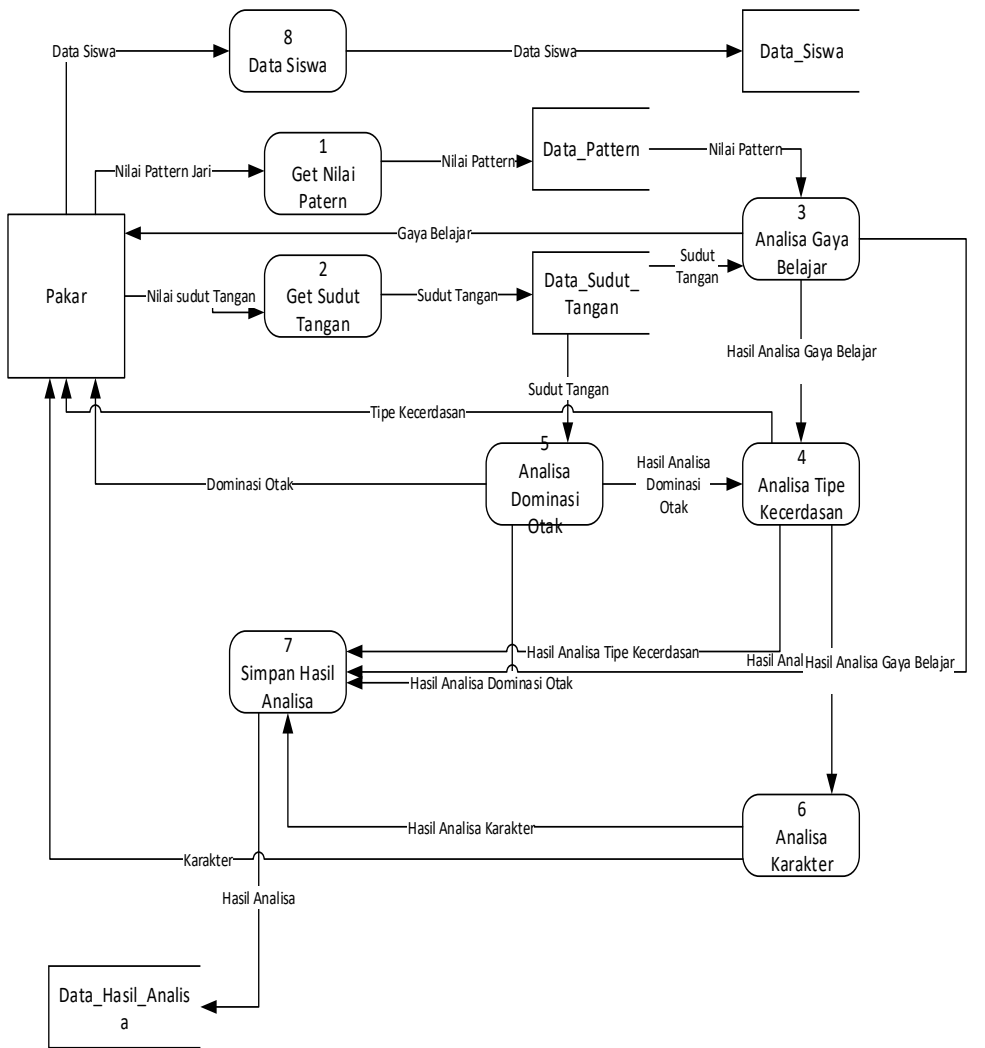

Gambar 5. Data flow diagram level 1

\section{Hasil Penelitian dan Pembahasan}

\subsection{Halaman Analisa}

Halaman analisa merupakan halaman yang berfungsi untuk menampilkan form inputan yang harus diisi oleh user yaitu data diri siswa yang akan di test, dan data patern jari. Berikut merupakan Gambar 6 dari halaman Analisa. 

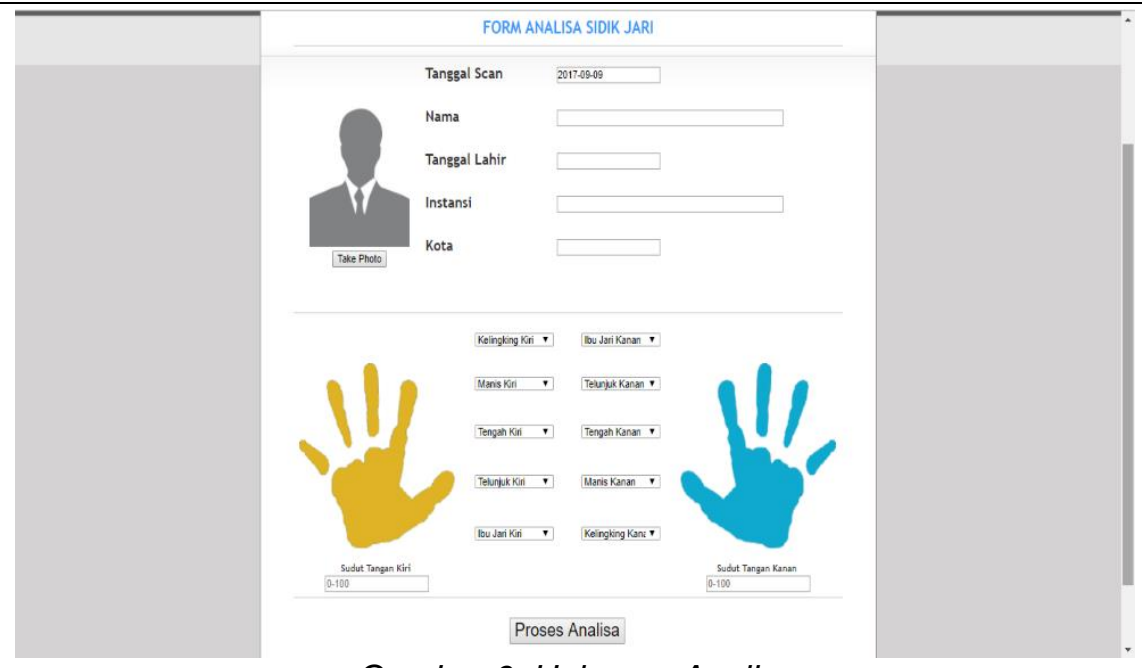

Gambar 6. Halaman Analisa

\subsection{Hasil Analisa Dominasi Otak}

Hasil dominasi otak akan menjelaskan tentang otak mana yang akan lebih dominan yang di hitung berdasarkan sudut tangan, dominasi otak yang di jelaskan adalah otak kiri dominan atau otak kanan dominan, jika otak kiri dominan maka system kerja otak lebih ke logika, kalkulasi, berbicara, membaca, menulis dan analisis, jika otak kanan dominan makan system kerja otak lebih banyak ke kepribadian, kreatifitas, intuisi, implementasi, kinerja dan seni. Berikut merupakan Gambar 7 dari halaman hasil dominasi otak.

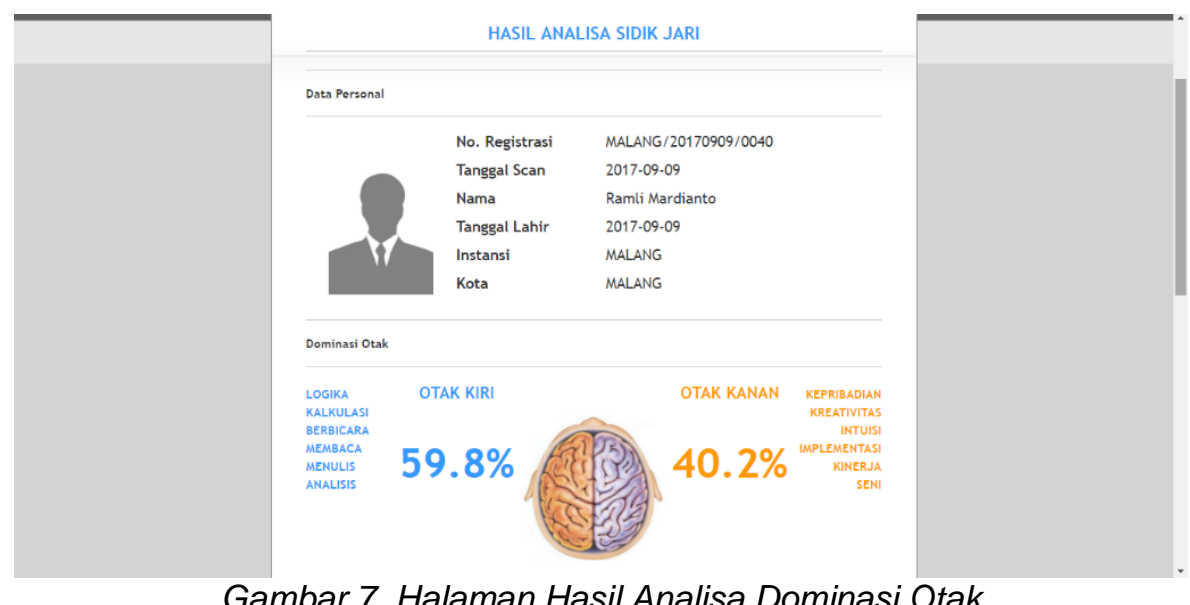

Gambar 7. Halaman Hasil Analisa Dominasi Otak

\subsection{Halaman Hasil Analisa Gaya Belajar}

Dari hasil dominasi otak maka akan di analisa selenjutnya yaitu analisa gaya belajar. Halaman hasil gaya belajar berfungsi untuk menampilkan grafik kecendrungan siswa agar lebih cepat menangkap materi yang di ajarkan. Hasil analisa gaya belajar menampilkan tiga gaya belajar tertinggi hasil analisa, berikut merupakan Gambar 8 halaman hasil analisa gaya belajar.

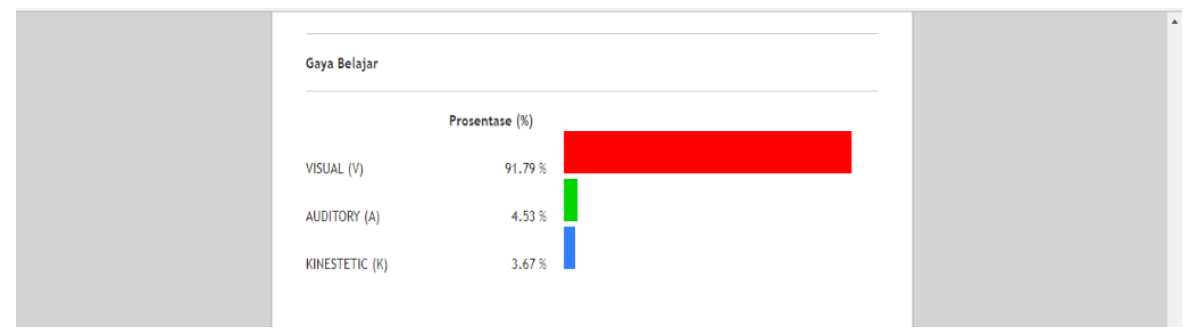

Gambar 8. Halaman Hasil Analisa Gaya Belajar 


\subsection{Halaman Hasil Analisa Tipe Kecerdasan}

Halaman hasil analisa tipe kecerdasan merupakan halaman yang berfungsi untuk menampilkan grafik tipe kecerdasan yang di miliki siswa, sehingga dapat membantu guru dalam memberikan materi, berikut merupakan Gambar 9 halaman hasil analisa tipe kecerdasan.

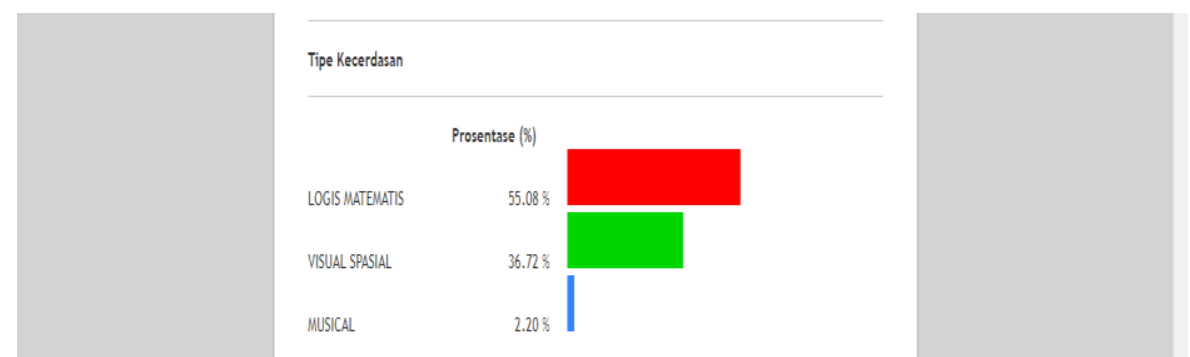

Gambar 9. Halaman Hasil Analisa Tipe Kecerdasan

\subsection{Halaman Hasil Analisa Karakter}

Selain dari analisa otak terdapat juga analisa karakter, analisa karakter berdasarkan analisa yang di ambil berdasarkan sidik jari dan analisa-analisa sebelumnya, analisa karakter berfungsi untuk penangan psikologi siswa, berikut merupakan Gambar 10 hasil analisa karakter.

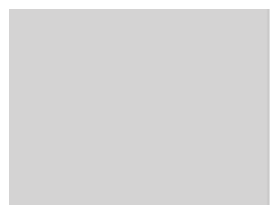

Karkter

\section{KOLERIS - MELANKOLLS - MELLANKOLLS}

\section{Gambar 10. Halaman Hasil Tipe Karakter}

\subsection{Tahap Pengujian}

Setelah dilakukan rancangan maka berikut adalah hasil dari pengujiannya, pengujian sistem yang digunakan adalah pengujian blackbox atau pengujian fungsioanal sistem, Tabel 6 berikut merupakan hasil dari pengujian fungsional system.

Tabel 6. Pengujian Fungsional Sistem

\begin{tabular}{|c|c|c|c|}
\hline Data masukan & Yang diharapkan & Pengamatan & Kesimpulan \\
\hline Halaman utama & $\begin{array}{ll}\text { Menampilkan } & \\
\text { Halaman } & \text { utama } \\
\text { aplikasi } & \end{array}$ & $\begin{array}{l}\text { Dapat Menampilkan } \\
\text { informasi yang di } \\
\text { inginkan. }\end{array}$ & $\begin{array}{l}{[\checkmark] \text { diterima }} \\
{\left[\begin{array}{c}\text { ] ditolak }\end{array}\right.}\end{array}$ \\
\hline $\begin{array}{l}\text { Halaman } \\
\text { analisa }\end{array}$ & $\begin{array}{l}\text { Menampilkan form } \\
\text { analisa }\end{array}$ & $\begin{array}{l}\text { Dapat menampilkan } \\
\text { form Analisa. }\end{array}$ & $\begin{array}{l}{[\checkmark \text { ] diterima }} \\
{[\quad] \text { ditolak }}\end{array}$ \\
\hline $\begin{array}{l}\text { Halaman hasil } \\
\text { analisa } \\
\text { dominasi otak }\end{array}$ & $\begin{array}{l}\text { Menampilkan } \\
\text { halaman hasil analisa } \\
\text { dominasi otak }\end{array}$ & $\begin{array}{l}\text { Dapat menampilkan } \\
\text { halaman hasil analisa } \\
\text { dominasi otak. }\end{array}$ & $\begin{array}{l}{[\checkmark] \text { diterima }} \\
{[\quad] \text { ditolak }}\end{array}$ \\
\hline $\begin{array}{ll}\text { Halaman } & \text { hasil } \\
\text { analisa } & \text { gaya } \\
\text { belajar } & \end{array}$ & $\begin{array}{l}\text { Menampilkan } \\
\text { halaman hasil analisa } \\
\text { gaya belajar }\end{array}$ & $\begin{array}{l}\text { Dapat menampilkan } \\
\text { halaman hasil analisa } \\
\text { gaya belajar. }\end{array}$ & $\begin{array}{l}{[\checkmark] \text { diterima }} \\
{[\quad] \text { ditolak }}\end{array}$ \\
\hline $\begin{array}{lr}\text { Halaman } & \text { hasil } \\
\text { analisa } & \text { tipe } \\
\text { kecerdasan } & \end{array}$ & $\begin{array}{l}\text { Menampilkan } \\
\text { halaman hasil analisa } \\
\text { tipe kecerdasan }\end{array}$ & $\begin{array}{l}\text { Dapat menampilkan } \\
\text { halaman hasil analisa } \\
\text { tipe kecerdasan. }\end{array}$ & $\begin{array}{l}{[\checkmark] \text { diterima }} \\
{[\quad] \text { ditolak }}\end{array}$ \\
\hline $\begin{array}{l}\text { Halaman hasil } \\
\text { analisa karakter }\end{array}$ & $\begin{array}{l}\text { Menampilkan } \\
\text { halaman hasil analisa } \\
\text { karakter }\end{array}$ & $\begin{array}{l}\text { Dapat menampilkan } \\
\text { halaman hasil analisa } \\
\text { karakter. }\end{array}$ & 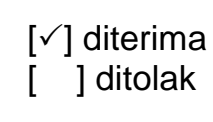 \\
\hline $\begin{array}{l}\text { Halaman } \\
\text { laporan }\end{array}$ & $\begin{array}{l}\text { Menampilkan } \\
\text { rekaputulasi hasil test } \\
\text { setiap siswa }\end{array}$ & $\begin{array}{l}\text { Dapat menampilkan } \\
\text { rekaputulasi hasil test } \\
\text { setiap siswa. }\end{array}$ & $\begin{array}{l}{[\checkmark] \text { diterima }} \\
{[\quad] \text { ditolak }}\end{array}$ \\
\hline Halaman help & $\begin{array}{l}\text { Menampilkan } \\
\text { halaman help }\end{array}$ & $\begin{array}{l}\text { Dapat menampilkan } \\
\text { halaman help. }\end{array}$ & $\begin{array}{l}{[\checkmark] \text { diterima }} \\
{[\quad] \text { ditolak }}\end{array}$ \\
\hline
\end{tabular}

REPOSITOR, Vol. 1, No. 1, November 2019: 17-26 
5. Kesimpulan dan Saran

Kesimpulan dari hasil penelitian ini adalah:

Setelah melalui proses rancang bangun dan pengujian system analisa sidik jari ini dapat diambil kesimpulan sebagai berikut:

1. Sistem dapat melakukan analisis berdasarkan pola sidik jari dan sudut tangan untuk mendapatkan tipe kecedasan, gaya belajar dan karakter pada anak.

2. Hasil kuesioner UAT (User Acceptance Test) dapat dikatakan baik karena memperoleh hasil dengan persentase lebih dari $80 \%$ yaitu sebesar $83 \%$.

3. Berdasarkan hasil pengujian, sistem analisa sidik jari ini dapat berjalan dengan baik secara fungsional sistem dan dapat menghasilkan output yang diharapkan. Sehingga dapat disimpulkan sistem analisa sidik jari ini sudah sesuai dengan tujuan utama pembuatan aplikasi.

Beberapa saran yang saya berikan untuk pengembangan selanjutnya adalah:

1. Tampilan aplikasi perlu dikembangkan agar menjadi lebih baik dan nyaman pada saat digunakan.

2. Dapat terintergrasi dengan system informasi sekolah sehingga dapat memetakan siswa berdasarkan kelas.

\section{Referensi}

[1] Daniel Setiadikarunia., "Identifikasi Karakter Seseorang Berdasarkan Pola Sidik Jari Tangan Dengan Ekstraksi Ciri Momen Invarian," vol. 03, no.09, Jan - Mar 2014.

[2] Cummins H.,"Finger Print, Palm and Soles An Introduction To Dermatoglyhics," The blakiston company, Philadelphia 1943.

[3] Galton F., "Finger Prints," Macmillan, London 1892.

[4] I Gede Sujana E. P., "Pengenalan Keperibadian Seseorang Berdasarkan Sisik Jari Dengan Metode Fuzzy Learning Vector Quantization Dan Fuzzy Backpropagation," vol. 13, no. 2 julidesember 2014.

[5] Polikar R., "Ensemble Based Systems in Decision Making," IEEE circuits syst mag, vo. 6, no. 12006.

[6] Komarinski P.,"Automated Fingerprint Identification Systems (AFIS)," MA: Elsevier academic press, Burlington 2005.

[7] Prasetyo J.J.R, dan Yeni Andriani., "Multiply Your Multiple Intelegences," Andi, Yogjakarta 2009.

[8] Martinis Yamin., "Strategi Belajar Mengajar," Gaung persada press, Jakarta (2004): 69.

[9] Andri Kristanto., "Perancangan Sistem Informasi dan Aplikasinya," Gava media, Jakarta 2003.

[10] Andri Kristanto., "Perancangan Sistem Informasi dan Aplikasinya," Gava media, Yogyakarta (2008): 70. 
REPOSITOR, Vol. 1, No. 1, November 2019: 17-26 